\title{
Fornecimento de grão de milheto, inteiro ou triturado, em duas frequências de suplementação para bovinos de corte ${ }^{1}$
}

\author{
João Marcos Beltrame Benatti ${ }^{2}$, Eduardo Henrique Bevitori Kling de Moraes ${ }^{3}$, Joanis \\ Tilemahos Zervoudakis ${ }^{4}$, Cláudio Vieira de Araújo ${ }^{5}$, Luciano da Silva Cabral ${ }^{4}$, João Rufino \\ Junior $^{6}$, Daniel Marino Guedes de Carvalho ${ }^{7}$
}

1 Pesquisa financiada pelo CNPq.

2 Programa de Pós-Graduação em Ciência Animal, UFMT, Cuiabá-MT.

3 CAA/Zootecnia/UFMT, Sinop-MT, 78557-267. Pesquisador do INCT-Ciência Animal.

${ }^{4}$ DPA/FAMEVIUFMT, Cuiabá-MT. Bolsista do CNPq; Pesquisador do INCT-Ciência Animal.

5 CAA/Zootecnia/UFMT, Sinop-MT, 78557-267. Bolsista do CNPq.

${ }^{6}$ Programa de Pós-Graduação em Zootecnia, UFGD, Dourados-MS.

7 Programa de Pós-Graduação em Agricultura Tropical, UFMT, Cuiabá-MT.

RESUMO - Objetivou-se avaliar o processamento do grão de milheto inteiro ou triturado em suplementos fornecidos diariamente ou três vezes por semana para bovinos de corte em pastejo e seus efeitos sobre o desempenho produtivo e econômico e o comportamento ingestivo diurno durante o período da seca. Utilizaram-se 25 bovinos nelores não-castrados, com peso inicial de 350,92 $\pm 31,7 \mathrm{~kg}$, mantidos em cinco piquetes com área unitária de 1,45 ha formados por B. brizantha cv Marandu. Os animais foram distribuídos em delineamento inteiramente casualizado em esquema fatorial $2 \times 2+1$, composto de duas formas físicas do grão de milheto (inteiro ou triturado), duas frequências de suplementação (diária ou três vezes por semana) e um tratamento controle (mistura mineral). A suplementação concentrada promoveu ganho de peso, enquanto a suplementação apenas com minerais acarretou perdas de peso de $0,16 \mathrm{~kg} / \mathrm{animal} / \mathrm{dia}$. A moagem do grão de milheto proporcionou maiores ganhos $(0,36$ e $0,38 \mathrm{~kg} /$ animal/dia nos grupos com suplementação 3 e 7 vezes por semana, respectivamente), em comparação ao fornecimento de grão inteiro $(0,22$ e $0,24 \mathrm{~kg} / \mathrm{animal} / \mathrm{dia}, 3$ e 7 vezes por semana, respectivamente), enquanto as frequências de suplementação estudadas não promoveram diferenças nestas variáveis. Foi encontrado efeito significativo da interação dia $\times$ tratamento para tempo gasto com consumo de suplemento, pastejo e hidratação. Para o tempo em ócio, foi encontrada diferença entre o grupo controle e os demais. Maior retorno econômico foi obtido quando se ofertou milheto triturado e em menor frequência de suplementação (R\$ 22,70/animal). A utilização de suplementos múltiplos, assim como o processamento do grão de milheto, possibilita maiores ganhos de peso, independentemente da frequência de suplementação estudada, sendo que o fornecimento de suplemento 3 vezes por semana reduz os custos da suplementação.

Palavras-chave: desempenho, distribuição de suplementos, processamento do grão, seca, suplementos múltiplos

\section{Supply of whole or ground millet grain at two frequencies of supplementation for beef cattle}

\begin{abstract}
The objective was to evaluate the processing of the grain of millet in supplements given daily or three times a week to grazing beef cattle on productive performance, economic and diurnal intake behavior during the drought period. Twenty-five non-castrated Nelore cattle with initial body weight of $350.92 \pm 31.7 \mathrm{~kg}$ were kept in five paddocks with unit area of 1.45 ha formed by B. brizantha cv. Marandu. The animals were distributed in a completely radomized design in a $2 \times 2+1$ factorial arrangement, as follows: two physical forms of the grain of millet (whole or ground), two frequencies of supplementation (daily or three times a week) and the control treatment (mineral mix). It was found that the concentrate supplementation promoted weight gains, while sole mineral supplementation resulted in weight loss of $0.16 \mathrm{~kg} / \mathrm{animal} / \mathrm{day}$. Grinding the millet grain promoted higher gains $(0.36$ and $0.38 \mathrm{~kg} /$ animal/day for 3 and 7 times a week, respectively) when compared with the whole grain ( 0.22 and $0.24 \mathrm{~kg} /$ animal/day for 3 and 7 times a week, respectively), with no differences between the frequencies of supplementation. Significant effect of the day $\times$ treatment interaction was found for time in the trough, grazing and drinking water. For the resting time difference was found between the control treatment and the others. Greater economic return was achieved when ground millet was supplied at lower supplementation frequency (R\$22,70/animal). The use of multiple supplements, as well as the processing of millet grain, enabled greater weight gain, regardless of the supplementation frequency studied. Providing supplement 3 times a week reduces the costs with supplementation.
\end{abstract}

Key Words: distribution of supplements, dry period, grain processing, multiple supplements, performance 


\section{Introdução}

A produção de bovinos de corte no Brasil é baseada principalmente em pastagens com forragens tropicais e possui como ponto crítico a variação estacional durante o ano. Essas oscilações na oferta e no suprimento de nutrientes são fatores determinantes da necessidade de suplementação para elevação da produtividade. Todavia, com a inclusão de concentrados na dieta, surge a necessidade de distribuí-los aos animais, fato que eleva os custos desta prática (Figueiredo et al., 2007). Neste sentido, estratégias de fornecimento de suplemento são requeridas no intuito de reduzir despesas com combustível, mão-de-obra e depreciação de maquinários.

A suplementação em intervalos maiores que um dia tem se mostrado eficiente, pelo fato de os ruminantes manterem menores oscilações nos níveis de amônia ruminal, o que garantiria adequada fermentação entre os eventos de suplementação (Moraes et al., 2010). No entanto, a redução na frequência de suplementação para animais consumindo forrageiras de clima tropical e em condições de pastejo ainda é pouco conhecida e os resultados podem ser variáveis (Berchielli et al., 2006).

$\mathrm{O}$ crescimento da área plantada de milheto no Brasil, principalmente no Centro-Oeste, tem proporcionado maior oportunidade de utilização dos grãos dessa gramínea na alimentação animal (Bastos et al., 2005). Todavia, em virtude de seu tamanho reduzido, o processamento físico desses grãos traz gastos adicionais, devido ao menor rendimento dos moinhos nas fábricas de ração. Segundo Bolzan et al. (2007), a moagem dos cereais para alimentação de ruminantes aumenta a área superficial de contato e, assim, facilita os processos digestivos, tanto fermentativos quanto enzimáticos. Dessa forma, estudos sobre a utilização do grão de milheto e seu processamento físico para a alimentação de ruminantes tornam-se de grande interesse.

Desse modo, objetivou-se avaliar a influência do fornecimento do grão de milheto inteiro ou triturado em suplementos múltiplos ofertados diariamente ou três vezes por semana sobre o desempenho produtivo e econômico e o comportamento diurno de bovinos de corte mantidos em pastagens de capim-marandu.

\section{Material e Métodos}

O experimento foi conduzido no período da seca, entre os meses de agosto e outubro de 2008, no Setor de Bovinocultura de Corte da Fazenda Experimental da UFMT, município de Santo Antônio de Leverger, Mato Grosso.
Utilizaram-se 25 bovinos nelores, não-castrados, com peso corporal inicial de $350,92 \pm 31,7 \mathrm{~kg}$ e idade média de 20 meses. Os animais foram distribuídos aleatoriamente em grupos de cinco alojados em cinco piquetes com 1,45 ha cada, formados com Brachiaria brizantha cv. Marandu, providos de bebedouros e comedouros cobertos. Visando reduzir a influência de possíveis variações de ambiente, cada lote permaneceu em cada piquete por 14 dias procedendo-se, ao final desse período, à rotação entre eles. Adotou-se o método de pastejo de lotação contínua, com taxa de lotação fixa. No início do experimento, todos os animais foram submetidos ao controle de endo e ectoparasitas.

$\mathrm{O}$ experimento foi conduzido em delineamento inteiramente casualizado, em esquema fatorial $2 \times 2+1$, sendo: suplementos constituídos por grão de milheto (Pennisetum americanum (L.) Leeke) em duas formas físicas (inteiro ou triturado), duas frequências de suplementação (diária ou 3 vezes por semana) e o tratamento mistura mineral. Os suplementos foram fornecidos sempre às $10 \mathrm{~h}$, seguindo uma distribuição semanal de $14 \mathrm{~kg}$ de concentrado por animal. As combinações entre as formas físicas do grão e as frequências de suplementação constituíram os seguintes tratamentos: grão de milheto inteiro fornecido diariamente $(2 \mathrm{~kg} / \mathrm{animal} / \mathrm{dia})$; grão de milheto triturado fornecido diariamente $(2 \mathrm{~kg} / \mathrm{animal} / \mathrm{dia})$; grão de milheto inteiro fornecido às segundas, quartas e sextas-feiras (4,66 kg/animal/evento de suplementação); grão de milheto triturado fornecido às segundas, quartas e sextas-feiras (4,66 kg/animal/evento de suplementação); suplementação com mistura mineral (ad libitum).

Os suplementos (Tabela 1) foram formulados para proporcionar consumo correspondente a $0,55 \%$ do peso corporal (PC)/dia e suprir 69 e $42 \%$ das exigências diárias de proteína bruta e nutrientes digestíveis totais (NDT), respectivamente, de um novilho zebuíno, não-castrado, com $350 \mathrm{~kg}$ de PC e ganho esperado de $0,5 \mathrm{~kg} / \mathrm{dia}$, segundo recomendações de Valadares Filho et al. (2006). A taxa de lotação média no período experimental foi de 2,76 UA/ha.

Tabela 1 - Composição dos suplementos, com base na matéria natural

\begin{tabular}{lc}
\hline Ingredientes & $(\%)$ \\
\hline Mistura mineral ${ }^{1}$ & 2,5 \\
Uréia/Sulfato de amônio $(9: 1)$ & 3,0 \\
Farelo de algodão alta energia $\left(\right.$ Bunge $\left.^{\circledR}\right)$ & 39,5 \\
Grão de milheto (triturado ou inteiro) & 55,0 \\
\hline${ }^{1}$ Níveis de garantia: cálcio, $198 \mathrm{~g} / \mathrm{kg}$; fósforo, $60 \mathrm{~g} / \mathrm{kg}$; sódio, $117 \mathrm{~g} / \mathrm{kg}$; \\
magnésio, $5,1 \mathrm{~g} / \mathrm{kg}$; enxofre, $12,6 \mathrm{~g} / \mathrm{kg}$; iodo, $17,7 \mathrm{~g} / \mathrm{kg}$; ferro, $125 \mathrm{mg} / \mathrm{kg}$; \\
selênio, $10,4 \mathrm{mg} / \mathrm{kg}$; cobalto, $80 \mathrm{mg} / \mathrm{kg}$; manganês, $527 \mathrm{mg} / \mathrm{kg}$; flúor, $700 \mathrm{mg} / \mathrm{kg}$; \\
cobre, $1.000 \mathrm{mg} / \mathrm{kg}$; zinco, $3.000 \mathrm{mg} / \mathrm{kg}$.
\end{tabular}

R. Bras. Zootec., v.41, n.4, p.941-950, 2012 
Para o processamento do grão de milheto, utilizou-se desintegrador de grãos munido de peneira com orifícios de 3,0 $\mathrm{mm}$. Após processado, o milheto apresentou aspecto de fubá grosso e não foi observada a presença de grãos inteiros.

O estudo foi composto de três períodos experimentais de 28 dias, totalizando 84 dias. Para cálculo do ganho de peso médio diário (GMD), utilizou-se a diferença entre o peso corporal ao final e no início do experimento, ambos após 16 horas de jejum de sólidos, sendo o resultado dividido pela quantidade de dias em experimento. Adotou-se como covariável o peso corporal inicial em jejum.

No primeiro dia de cada período experimental, procedeu-se à amostragem da forragem por meio de dois métodos: pelo primeiro método, a estimativa da massa de forragem foi realizada de maneira direta, pelo corte da forragem rente ao solo em cinco pontos de áreas delimitadas por um quadrado metálico de $0,5 \times 0,5 \mathrm{~m}\left(0,25 \mathrm{~m}^{2}\right)$ e representativas da condição média de cada piquete, seguindo uma estimativa visual.

Após a coleta, cada amostra foi pesada e homogeneizada. Para avaliação da massa total de matéria seca (MS) de forragem $(\mathrm{kgMS} / \mathrm{ha})$, foi colhida uma subamostra, acondicionada em saco plástico, identificada e analisada posteriormente. Outra subamostra foi colhida e utilizada para separação dos componentes morfológicos da forragem: lâmina foliar verde, pseudocolmo (colmo + bainha) verde, lâmina foliar seca e pseudocolmo seco, sendo a inflorescência, quando encontrada, considerada pseudocolmo.

Também foram feitas amostragens de forragem pelo método de simulação manual de pastejo (pastejo simulado) (segundo método), realizadas de acordo com Johnson (1978). A coleta foi realizada por um único amostrador em todo o período experimental, a fim de evitar variações em cada amostragem.

Das amostras destinadas à estimativa da massa total de MS de forragem, foi calculado o percentual de MS potencialmente digestível (MSpD). Esse resultado foi obtido por meio do resíduo insolúvel em detergente neutro (FDNi) avaliado após incubação in situ das amostras por 240 horas em sacos de tecido-não-tecido (TNT $\left.-100 \mathrm{~g} / \mathrm{m}^{2}\right)$ (Casali et al., 2008), segundo a equação: $\mathrm{MSpD}=0,98 \mathrm{X}(100-$ FDN $)+($ FDN - FDNi $)$; em que: $0,98=$ coeficiente de digestibilidade verdadeira do conteúdo celular; FDN = fibra em detergente neutro e $\mathrm{FDNi}=\mathrm{FDN}$ indigestível.

As amostras foram pré-secas em estufa com ventilação forçada a $55^{\circ} \mathrm{C}$ por 72 horas e, posteriormente, moídas em moinho de facas tipo Willey até atingirem granulometria de 1,0 mm para realização das análises laboratoriais. As análises químico-bromatológicas foram realizadas de acordo com descrições de Silva \& Queiroz (2002), com exceção das avaliações deFDN e FDA, que seguiram os métodos descritos por Mertens (2002) e Van Soest \& Robertson (1985), respectivamente. Os carboidratos totais (CT) foram calculados segundo metodologia descrita por Sniffen et al. (1992), em que CT $(\%)=100-(\% \mathrm{~PB}+\% \mathrm{EE}+\%$ Cinzas $)$. A quantificação dos carboidratos não-fibrosos (CNF) nos suplementos foi obtida de acordo com adaptação de Hall (2000). Os nutrientes digestíveis totais (NDT) estimados da forragem e dos suplementos foram calculados segundo equação sugerida pelo NRC (2001).

A oferta de forragem (OF) foi calculada de acordo com a equação:

$$
O F(\%)=\frac{M F X 100}{P C}
$$

em que: $\mathrm{OF}=$ oferta de forragem $(\%) ; \mathrm{MF}=$ massa de forragem/ha/dia $(\mathrm{kgMS} / \mathrm{ha} / \mathrm{dia}) ; \mathrm{PC}=$ peso corporal médio dos animais $(\mathrm{kg})$.

Para avaliação do comportamento ingestivo diurno, observou-se cada animal em intervalos de 10 minutos, anotando as variáveis comportamentais: pastejo, ruminação, ócio, hidratação e consumo de suplemento. A visualização foi feita entre $6 \mathrm{~h}$ e $18 \mathrm{~h}$ (12 horas/dia) durante dois dias consecutivos com a finalidade de se avaliar o comportamento em um dia em que os animais com menor frequência de suplementação não receberam suplemento (dia 1) e outro em que todos os animais receberam o suplemento (todos os tratamentos suplementados - dia 2).

Para a análise estatística referente ao desempenho, foram estabelecidas comparações entre tratamentos por meio da decomposição da soma dos quadrados relacionados a esta fonte por intermédio dos seguintes contrastes ortogonais: a) suplementação mineral versus suplementação concentrada; b) grão de milheto inteiro versus grão triturado; c) suplementação três vezes por semana versus diária; e d) interação entre forma física do grão de milheto e a frequência de suplementação. Foi utilizado o programa computacional SAS (Statistical Analysis System, versão 8.2) na análise dos resultados, adotando-se $\alpha=0,10$.

Para a análise referente ao comportamento ingestivo diurno, utilizou-se a teoria de modelos mistos, empregando-se o método de estimadores de máxima verossimilhança. O modelo misto utilizado é representado por:

$\mathrm{y}=\mu+\alpha_{\mathrm{i}}+\mathrm{d}_{\mathrm{ij}}+\gamma_{\mathrm{k}}+(\alpha \gamma)_{\mathrm{ik}}+\varepsilon_{\mathrm{ijk}}$, em que: $\mathrm{y}=$ resposta no dia $\mathrm{k}$ do indivíduo $\mathrm{j}$ no grupo de tratamento $i ; \mu=$ efeito médio geral; $\alpha_{i}=$ efeito fixo do tratamento $\mathrm{i} ; \mathrm{d}_{\mathrm{ij}}=$ efeito aleatório do indivíduo $\mathrm{j}$ no grupo de tratamento $\mathrm{i} ; \gamma_{\mathrm{k}}=$ efeito fixo do tempo $\mathrm{k} ;(\alpha \gamma)_{\mathrm{ik}}=$ efeito da interação fixa do tratamento i com o tempo k; $\varepsilon_{\mathrm{ijk}}=$ erro 
aleatório. Para a estrutura de covariância entre medidas repetidas de um mesmo indivíduo, a não-estruturada foi obtida como a de melhor ajuste pelo critério de Akaike (AIC). Adotou-se $\alpha=0,05$.

Para a análise econômica, foram utilizados os seguintes indicadores:

- ganho em peso total ( $\mathrm{kg} / \mathrm{animal})$ : diferença entre o peso corporal inicial e final em jejum;

- ganho em equivalente carcaça (@): ganho de peso total multiplicado pelo rendimento de carcaça, considerando $52 \%$ como valor referência;

- ganho de peso diário (g/animal/dia): ganho de peso total dividido pelos dias em experimento (84 dias);

- ganho de peso diferencial (g/animal/dia): superioridade dos grupos sob suplementação com concentrado em relação ao grupo controle, que recebeu mistura mineral;

- receita (R \$/animal): ganho em equivalente carcaça multiplicado pelo preço pago pela @ no período (R $\$ 89,00$ em outubro de 2008);

- consumo de suplemento ( $\mathrm{kg} / \mathrm{animal} / \mathrm{dia})$ : quantidade em quilogramas que cada animal consumiu por dia ( $\mathrm{kg}$ de suplemento fornecido em uma semana por animal dividida pela quantidade de dias em uma semana);

- custo do suplemento $(\mathrm{R} \$ / \mathrm{kg})$ : custo do suplemento no período (milheto $\mathrm{R} \$ 0,40 / \mathrm{kg}$; farelo de algodão $\mathrm{R} \$ 0,27 / \mathrm{kg}$; ureia $\mathrm{R} \$ 1,67 / \mathrm{kg}$; sulfato de amônio $\mathrm{R} \$ 1,35 / \mathrm{kg}$ e a mistura mineral $\mathrm{R} \$ 1,38 / \mathrm{kg}$ ). O custo do processamento do grão foi calculado com base na utilização de desintegrador de grãos com motor de $12,5 \mathrm{cv}$ com rendimento de $500 \mathrm{~kg} / \mathrm{hora}$ (peneira com orifício de $3 \mathrm{~mm}$ );

- custo do transporte (R $\$$ /animal): distância percorrida para o fornecimento do suplemento $(1 \mathrm{~km} /$ dia) durante o experimento multiplicada pelo custo do $\mathrm{km}$ rodado $(\mathrm{R} \$ 0,44)$ e dividido pela quantidade de animais por tratamento;

- custo da mão-de-obra (R \$/animal): preço da mão-deobra ( $\$$ 2,50/hora) multiplicado pelas horas gastas para cada evento de suplementação no período ( 0,3 hora) dividido pela quantidade de animais por tratamento;

- custo total (R\$/animal): soma dos custos com suplemento, transporte e mão-de-obra;

- custoda@produzida $(\mathrm{R} \$ / @)$ : ganho em equivalente carcaça dividido pelo custo total;

- valor pago pela@noperíodo (R\$/@): valor pago pela arroba no município de Cuiabá, Mato Grosso, em outubro de 2008 (CEPEA);

- margem bruta de lucro (R\$/animal): receita subtraída a despesa;

- ganho de peso diário mínimo necessário para cobriro custo da suplementação (kg/animal $/$ dia $): X=(15 \times Y) / 89)$ em que: $\mathrm{X}=$ quantidade em quilogramas ganhos por dia necessário para cobrir os custos com a suplementação; 15 = quantidade de quilogramas em uma @; Y= gasto com a suplementação em cada tratamento por animal e 89 o preço cotadoda@no período;

- remuneração do capital investido (\%): margem bruta de lucro dividida pelo custo total.

\section{Resultados e Discussão}

Com o passar dos meses, houve redução na massa total de matéria seca, em decorrência da época, que não favorece o crescimento das gramíneas; do pastejo exercido pelos animais e morte e degradação de alguns constituintes do dossel forrageiro (Figura 1).

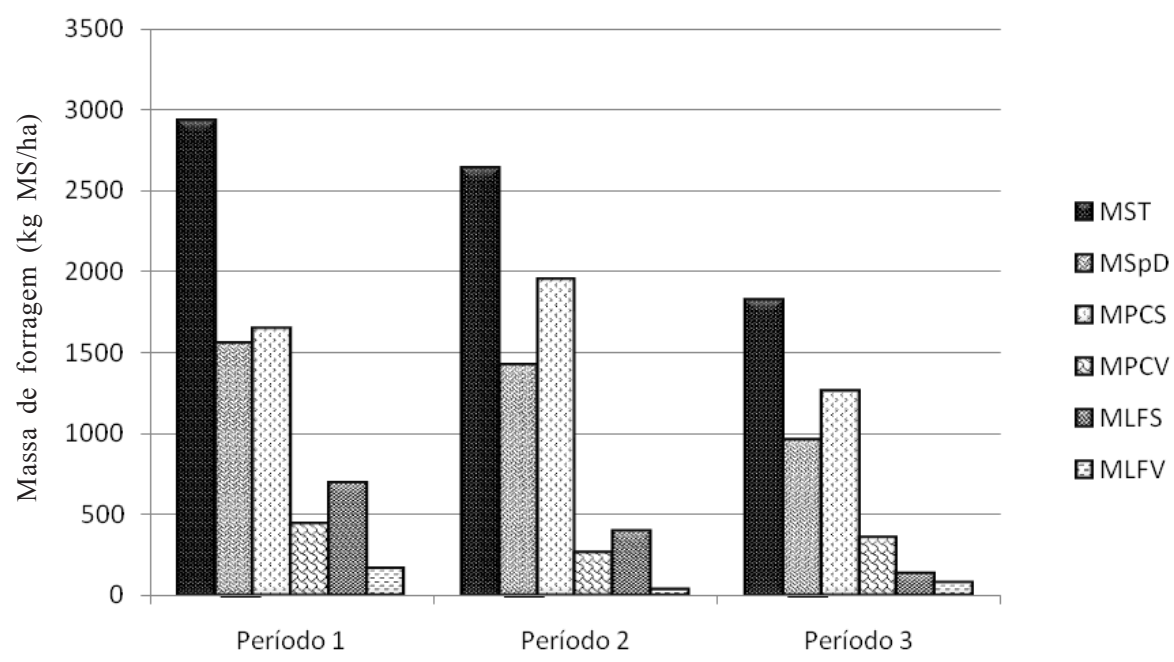

Figura 1 - Massa de matéria seca total (MST), matéria seca potencialmente digestível(MSpD), pseudocolmo seco (MPCS), pseudocolmo verde (MPCV), lâmina foliar seca (MLFS) e lâmina foliar verde (MLFV) durante os períodos experimentais. 
As médias de MLFS e MLFV reduziram conforme se passaram os meses, fato que pode ser explicado pelo fato de os bovinos terem selecionado o material colhido e por ser reduzida a taxa de crescimento das forrageiras nesse período. Entre os dois últimos períodos, elevaram-se as quantidades de materiais verdes, tanto pseudocolmos como lâminas foliares, como resultado do aparecimento de novos perfilhos, devido a precipitações que ocorreram nessa época.

$\mathrm{O}$ valor médio encontrado neste estudo para oferta de forragem (OF) foi de $6,56 \%$ e, para oferta de folhas, $1,32 \%$, com relação lâmina foliar:pseudocolmo média de 0,24.

Com relação aos valores encontrados para $\mathrm{MSpD}$, a massa para cada período experimental foi de $1.552,2 ; 1.416,8$ e $955,6 \mathrm{~kg} / \mathrm{ha}$, que correspondem a 52,$93 ; 53,8$ e $52,48 \%$ da matéria seca total para o primeiro, segundo e terceiro períodos, respectivamente. Segundo Paulino et al. (2004), os valores indicados para oferta de forragem potencialmente digestível são de 4 a 5\% do peso corporal (PC) em MSpD, visando associar produção por animal, por área e eficiência de uso. A MSpD foi de 3,6\% PC e revela a baixa disponibilidade de nutrientes passíveis de utilização pelas bactérias ruminais.

Os baixos valores encontrados para MSpD devem-se à alta proporção principalmente de pseudocolmos secos, que possuem parede celular altamente lignificada. Essa alta lignificação da parede celular limita a atividade microbiana sobre os polissacarídeos potencialmente digestíveis, o que compromete a degradação e disponibilização dos substratos dessa parede (Paulino et al. 2002).

A participação de pseudocolmos secos na massa forrageira foi alta em todos os períodos experimentais $(56,1$; 73,9 e $69,2 \%$ para o primeiro, segundo e terceiro períodos respectivamente). Segundo Euclides et al. (2001), pastagens submetidas ao regime de lotação contínua apresentarão com frequência resíduos de forragem não consumidos que continuam decrescendo em qualidade, principalmente em épocas secas em resposta a menor taxa de rebrota, desta forma a pastagem será uma combinação de rebrota e da forragem recusada.

A participação de material seco (lâminas foliares secas + pseudocolmos secos) em todos os períodos experimentais foi muito elevada, apresentando massa média de material seco de $2.336,4 ; 2.343,4 ;$ e $1.396,0 \mathrm{~kg} \mathrm{MS} / \mathrm{ha}$, representando 79,$7 ; 89,0 ;$ e $76,7 \%$ para o primeiro, segundo e terceiro períodos, respectivamente.

$\mathrm{Na}$ análise da constituição químico-bromatológica (Tabela 2) da forragem, a porcentagem de $\mathrm{PB}(4,45 \% \mathrm{~PB}$ na MS) na simulação do pastejo foi inferior à recomendada por Minson (1990), Van Soest (1994) e Lazzarini et al. (2009), de 7\%, como limite mínimo para atividade da microbiota ruminal.

Segundo Sampaio et al. (2009), a proteína é o nutriente mais limitante para adequada utilização de forrageiras tropicais de baixa qualidade, assim, a suplementação com compostos nitrogenados é recomendada para promover adequada condição para os microrganismos ruminais e melhorar a eficiência de utilização da fibra da forragem. No caso de parede celular, digestão requer uma população microbiana ativa com capacidade para digerir seus constituintes (Paulino et al., 2004). Assim, o consumo pode ser controlado pela repleção ruminal, devido às altas porcentagens de FDN na dieta com baixa taxa de degradação. Os altos teores de FDN, FDA, lignina e FDNi são resultado do estágio avançado de maturidade e da elevada quantidade de MS seca (órgãos secos da forragem) da forragem.

Tabela 2 - Composição bromatológica do suplemento, do pasto (simulação do pastejo) e suas frações (\%MS)

\begin{tabular}{|c|c|c|c|c|c|c|}
\hline & \multirow[t]{2}{*}{ Suplemento } & \multirow[t]{2}{*}{ Pasto } & \multicolumn{4}{|c|}{ Frações do pasto } \\
\hline & & & Lâmina foliar verde & Lâmina foliar seca & Pseudo colmo verde & Pseudo colmo seco \\
\hline MS (\%) & 91,25 & 62,06 & 37,00 & 81,53 & 46,97 & 78,19 \\
\hline PB & 27,06 & 4,45 & 9,78 & 2,88 & 1,90 & 1,59 \\
\hline $\mathrm{NDT}^{1}$ & 75,91 & 54,96 & 57,84 & 52,90 & 51,12 & 49,36 \\
\hline FDN & 29,18 & 75,24 & 66,68 & 77,54 & 80,17 & 83,24 \\
\hline $\mathrm{NIDN}^{2}$ & 30,77 & 61,43 & 55,13 & 76,09 & 83,24 & 96,00 \\
\hline NIDA $^{2}$ & 10,11 & 38,66 & 32,38 & 48,28 & 74,60 & 84,53 \\
\hline $\mathrm{EE}$ & 6,57 & 2,23 & 2,81 & 2,43 & 1,78 & 0,90 \\
\hline Cinzas & 4,76 & 7,46 & 11,01 & 8,72 & 6,34 & 5,49 \\
\hline Lignina & 6,18 & 8,24 & 4,50 & 5,39 & 6,01 & 13,43 \\
\hline $\mathrm{CT}$ & 61,62 & 81,61 & 76,40 & 85,97 & 89,98 & 92,02 \\
\hline
\end{tabular}

${ }^{1} \mathrm{NRC}(2001) ;{ }^{2} \% \mathrm{~N}$ total. 
$\mathrm{Na}$ avaliação do desempenho dos animais (Tabela 3), observou-se diferença significativa $(\mathrm{P}<0,01)$ entre os grupos sob suplementação e o controle (MM), tanto para PCF quanto para GMD. A utilização de suplementos concentrados promoveu ganho de peso em comparação à oferta de mistura mineral, que resultou em perdas de peso de aproximadamente $0,160 \mathrm{~kg} / \mathrm{dia}$.

Segundo Paulino et al. (2004), nos modelos produtivos tradicionais, com uso exclusivo de pastagens, os desequilíbrios nutricionais, especialmente no período outono-inverno, limitam a resposta produtiva animal e afetam a economia e sustentabilidade dos sistemas extensivos.

De acordo com Mertens (1994), o desempenho animal depende do consumo de nutrientes digestíveis totais e metabolizáveis, assim, quando em pastagens com menor massa de forragem e estrutura que dificulte a apreensão, o animal não tem a capacidade de colhê-la com eficiência e isso resulta em mais baixo desempenho.

Chacon \& Stobbs (1976) inferiram que, entre os vários fatores que poderiam controlar o consumo por animais a pasto, as características estruturais da gramínea teriam relação com a facilidade de preensão e seleção das mesmas. Hodgson (1990) citou como sendo três os fatores que influenciam o consumo por animais: fatores qualitativos da forragem que limitam a digestão, fatores relacionados ao estágio fisiológico dos animais e as características do dossel forrageiro.

Gomes Júnior et al. (2002) avaliaram a suplementação na estação seca mantendo animais com suplementação mineral e observaram baixos ganhos de peso (GMD de $0,09 \mathrm{~kg} / \mathrm{dia}$ ), mesmo quando os animais foram mantidos em piquetes com massa de forragem de $6.454 \mathrm{kgMS} / \mathrm{ha}$.

Ao comparar a forma física do grão de milheto, observou-se diferença $(\mathrm{P}<0,01)$ entre grãos triturados $\mathrm{e}$ inteiros, pois o processamento do mesmo resultou em maior ganho médio diário e maior peso corporal final. Segundo Beauchemin et al. (1994), grão inteiro com pericarpo intacto é muito ou totalmente resistente à digestão por ruminantes porque dificultam a adesão dos microrganismos.

Conforme relatado por Valadares Filho \& Pina (2006), a adesão ao substrato é o passo inicial no processo digestivo, contudo, para a digestão ocorrer, os microrganismos devem penetrar ou esquivar-se das barreiras resistentes na superfície das partículas do alimento, de modo a acessar os substratos. Bolzan et al. (2007) salientaram que a trituração de cereais visa aumentar a área superficial dos grãos para facilitar os processos digestivos, tanto fermentativos como enzimáticos.

Com os resultados obtidos, pode-se afirmar que os suplementos à base de grãos de milheto na forma triturada promoveram maior aporte de nutrientes passíveis de utilização em detrimento aos grãos sem processamento, fato comprovado pela resposta no desempenho. Moron et al. (2000), estudando formas de processamento do grão de milho e sorgo, observaram diferença no amido efetivamente degradado no rúmen para ambos os alimentos quando testados inteiros, quebrados, autoclavados, moídos e extrusados sendo que o grão sem nenhuma forma de processamento apresentou os resultados mais baixos, seguido pelos quebrados, autoclavados, moídos e extrusados, respectivamente.

A pronta utilização dos nutrientes oriundos do grão de milheto processado, principalmente dos carboidratos nãofibrosos, pode ter favorecido o crescimento bacteriano, uma vez que o suplemento forneceu, além de energia, quantidade de ureia e sulfato de amônio como fonte de nitrogênio e enxofre para síntese de proteína bacteriana juntamente com proteína verdadeira. De acordo com Van Soest (1994), grande parte da energia utilizada pelos microrganismos que degradam a fibra da forragem é oriunda da amônia, no entanto, concentrações de carboidratos de rápida fermentação são requeridas para maior eficiência na síntese microbiana, uma vez que a fibra da forragem e as fontes de nitrogênio, como a proteína verdadeira e o NNP, possuem taxas de fermentação diferentes.

As frequências de suplementação não influenciaram $(\mathrm{P}>0,10)$ o ganho médio diário, independentemente da forma física do grão de milheto, corroborando as afirmações de Bohnert et al. (2002) de que o controle de fornecimento de suplemento intercalando dias com suplementação e sem suplementação em animais submetidos a uma pastagem de baixa qualidade, propicia desempenho e eficiência de

Tabela 3 - Peso corporal final (PCF) e ganho de peso médio diário (GMD) de bovinos sob suplementação com grão de milheto inteiro ou triturado fornecido diariamente ou 3 vezes por semana

\begin{tabular}{|c|c|c|c|c|c|c|c|c|c|c|}
\hline & \multirow{2}{*}{$\begin{array}{l}\text { Mistura } \\
\text { mineral }\end{array}$} & \multicolumn{2}{|c|}{ Milheto inteiro } & \multicolumn{2}{|c|}{ Milheto triturado } & \multirow[t]{2}{*}{ CV $(\%)$} & \multicolumn{4}{|c|}{ Contraste } \\
\hline & & $3 \mathrm{X} /$ semana & $7 \mathrm{X} /$ semana & $3 \mathrm{X} /$ semana & $7 \mathrm{X} /$ semana & & A & B & $\mathrm{C}$ & D \\
\hline $\mathrm{PCF}$ & 340 & 371 & 367 & 377 & 388 & 11,30 & $<0,0001$ & $<0,0001$ & 0,3150 & 0,5739 \\
\hline GMD & $-0,16$ & 0,22 & 0,24 & 0,36 & 0,38 & 12,32 & $<0,0001$ & $<0,0001$ & 0,3283 & 0,5117 \\
\hline
\end{tabular}

A: tratamento controle versus suplementação; B: grão de milheto inteiro versus grão de milheto triturado; C: suplementação 3 vezes/semana versus diária; D: interação entre forma física do grão de milheto e frequência de suplementação. 
utilização do nitrogênio similar aos de animais sob suplementação diária.

Da mesma forma, Canesin et al. (2007) avaliaram três estratégias de suplementação sobre o ganho de peso de bovinos fornecendo $1 \%$ do PC em suplemento (média do fornecimento semanal) e não encontraram diferença entre as frequências de fornecimento de suplemento. Em contrapartida, Paula et al. (2010), estudando suplementos (fornecidos em quantidade média de $1 \mathrm{~kg} / \mathrm{animal} / \mathrm{dia}$ ) com diferentes fontes proteicas (farelo de soja e farelo de algodão alta energia) e frequências de suplementação (diária e três vezes por semana), observaram efeito das fontes proteicas utilizadas e das frequências de fornecimento dos suplementos sobre o ganho médio diário dos animais, cujos melhores valores foram obtidos com a oferta de farelo de soja e o fornecimento em dias intercalados. Segundo esse último autor, uma possível explicação para a superioridade dos animais sob suplementação em menor frequência é que os animais não consumiram todo o suplemento de uma vez, o que teria diminuído as divergências no consumo entre os animais (redução nas disputas e/ou dominâncias).

Por sua vez, Garcia et al. (2005) avaliaram o desempenho de bovinos submetidos ao método de lotação contínua no período seco, com massa de forragem de $4.204 \mathrm{~kg} \mathrm{MS} / \mathrm{ha} \mathrm{e}$ suplementos fornecidos em duas frequências (diária e três vezes por semana) e observaram que a distribuição intercalada de suplementos influenciou negativamente o desempenho dos animais, que apresentaram ganhos de 234 e $124 \mathrm{~g}$ fornecimento diário e alternado, respectivamente.

Lampierre \& Lobley (2001) mencionaram que a ureia reciclada e que volta ao trato gastrintestinal representa 30 a $40 \%$ do nitrogênio ingerido por bovinos, sendo que aproximadamente $50 \%$ deste pode ser convertido em produtos anabólicos, um mecanismo vital para conservar $\mathrm{N}$ e manter uma provisão de aminoácidos aos tecidos periféricos. Dessa forma, deduz-se que os animais que receberam suplementação três vezes por semana foram capazes de manter a concentração de amônia ruminal via reciclagem de ureia durante os dias sem suplementação, propiciando às bactérias ruminais concentrações de nitrogênio para crescimento, uma vez que a forragem apresentou baixa quantidade de PB (4,45\% MS), mantendo adequada condição ruminal para a digestão da fibra.

Com relação às observações comportamentais dos animais (Tabela 4), constatou-se que, para as variáveis aleatórias consumo de suplemento e pastejo, houve efeito significativo da interação dia $\times$ tratamento $(P<0,01)$. Nos dias sem suplementação, o tempo despendido pelos animais no consumo suplemento foi de zero minuto, e isso comprova que consumiram todo o concentrado no mesmo dia do evento de suplementação. No dia em que todos os animais receberam suplementação (dia 2), foi maior o tempo gasto

Tabela 4 - Médias (minutos/12 horas) para as variáveis cocho, ócio, água, ruminação e pastejo em bovinos sob suplementação com grão de milheto inteiro ou triturado fornecido diariamente ou 3 vezes por semana

\begin{tabular}{|c|c|c|c|c|c|c|}
\hline \multirow[t]{2}{*}{ Dias } & \multirow[t]{2}{*}{ Mistura mineral } & \multicolumn{2}{|c|}{ Milheto inteiro } & \multicolumn{2}{|c|}{ Milheto triturado } & \multirow[t]{2}{*}{ Média } \\
\hline & & 3 vezes/seman & 7 vezes/semana & 3 vezes/semana & 7 vezes/semana & \\
\hline \multicolumn{7}{|c|}{ Consumo de suplemento } \\
\hline Dia 1 & $1,16 \mathrm{bA}$ & $0,00 \mathrm{cB}$ & $45,37 \mathrm{aA}$ & $0,00 \mathrm{cB}$ & $56,55 \mathrm{aA}$ & 20,62 \\
\hline Dia 2 & $2,30 \mathrm{cA}$ & $82,98 \mathrm{bA}$ & $46,03 \mathrm{aA}$ & $82,16 \mathrm{bA}$ & $46,68 \mathrm{aA}$ & 52,03 \\
\hline Média & 1,73 & 41,49 & 45,70 & 41,08 & 51,62 & 36,32 \\
\hline \multicolumn{7}{|c|}{ Ócio } \\
\hline Dia 1 & 81,19 & 183,59 & 149,26 & 189,37 & 178,19 & 156,32 \\
\hline Dia 2 & 91,39 & 165,31 & 156,63 & 167,67 & 161,09 & 148,42 \\
\hline Média & $86,29 b$ & $174,45 \mathrm{a}$ & $152,95 \mathrm{a}$ & $178,52 \mathrm{a}$ & $169,64 \mathrm{a}$ & 152,37 \\
\hline \multicolumn{7}{|c|}{ Consumo de água } \\
\hline Dia 1 & 18,09 & 28,27 & 28,93 & 21,04 & 26,30 & $24,53 \mathrm{~B}$ \\
\hline Dia 2 & 19,07 & 31,56 & 27,47 & 26,30 & 27,62 & $26,40 \mathrm{~A}$ \\
\hline Média & $18,58 \mathrm{~b}$ & $29,92 \mathrm{a}$ & $28,20 \mathrm{a}$ & $23,67 \mathrm{a}$ & $26,96 a$ & 25,47 \\
\hline \multicolumn{7}{|c|}{ Ruminação } \\
\hline Dia 1 & 88,11 & 91,39 & 67,72 & 100,60 & 71,67 & 83,90 \\
\hline Dia 2 & 107,17 & 82,19 & 82,19 & 80,87 & 82,19 & 86,92 \\
\hline Média & 97,64 & 86,79 & 74,96 & 90,74 & 76,93 & 85,41 \\
\hline \multicolumn{7}{|c|}{ Pastejo } \\
\hline Dia 1 & $531,44 \mathrm{bA}$ & $416,74 \mathrm{aB}$ & $428,71 \mathrm{aA}$ & $408,97 \mathrm{aB}$ & $387,28 \mathrm{aA}$ & 434,63 \\
\hline Dia 2 & $500,05 \mathrm{cA}$ & $357,94 \mathrm{bA}$ & $407,67 \mathrm{aA}$ & $362,98 \mathrm{bA}$ & $402,41 \mathrm{aA}$ & 406,21 \\
\hline Média & 515,75 & 387,34 & 418,19 & 385,98 & 420,42 & 420,42 \\
\hline
\end{tabular}

Médias seguidas de letras maiúsculas diferentes na coluna indicam diferenças entre frequências de suplementação em cada tipo de suplemento.

Médias seguidas de letras minúsculas diferentes na linha indicam diferenças entre suplementos em cada frequência de suplementação. 
no consumo de suplemento pelos animais do grupo sob suplementação 3 vezes por semana, devido à maior quantidade de concentrado fornecido nesse dia. Não houve diferença $(\mathrm{P}>0,05)$ entre a forma física do grão nem entre os dias de avaliação dentro da frequência de suplementação de 7 vezes por semana (diária).

Os tempos gastos em ócio e no consumo de água foram influenciados $(\mathrm{P}<0,10)$ pelo efeito da suplementação, e esta busca por água também sofreu influência $(\mathrm{P}<0,01)$ dos dias de avaliação. O maior tempo despendido pelos animais no dia 2 com hidratação pode ter sido devido à maior quantidade de matéria seca de suplemento consumida nesse dia pelos animais sob suplementação 3 vezes por semana. $\mathrm{O}$ tempo de ruminação não foi influenciado $(\mathrm{P}>0,05)$ por nenhum fator estudado.

Os animais que receberam apenas mistura mineral apresentaram maior tempo de pastejo $(\mathrm{P}<0,01)$, não havendo diferença $(\mathrm{P}>0,05)$ entre os dias estudados. Houve diferença $(\mathrm{P}<0,01)$ entre dias de avaliação para a suplementação 3 vezes por semana, uma vez que no dia 1 os animais pastejaram por mais tempo. No dia 2, os mesmos animais tiveram menor $(\mathrm{P}<0,01)$ tempo em pastejo, devido ao maior $(\mathrm{P}<0,01)$ tempo gasto com consumo de suplemento e hidratação. Segundo Hodgson (1990), quando animais recebem suplemento, novas variáveis interferem no consumo de nutrientes e estão associadas às relações de substituição de forragem por suplemento e/ou à adição no consumo total de matéria seca, que mudam conforme as características da base forrageira e do suplemento.

Com relação aos índices econômicos (Tabela 5), observou-se que o custo com o processamento do grão de milheto aumentou o preço do suplemento. $\mathrm{O}$ valor gasto com transporte foi maior para a suplementação diária e o mais baixo, para a suplementação com mistura mineral, uma vez que o fornecimento foi feito apenas uma vez por semana. Também, os gastos com mão-de-obra reduziram consideravelmente com a redução na frequência de distribuição dos suplementos.

Os maiores valores por arroba produzida foram obtidos para a suplementação com grão de milheto inteiro em comparação àquelas com grão de milheto triturado. A margem bruta de lucro seguiu o mesmo padrão: quanto menores os valores, menor o ganho observado.

Para a remuneração do capital investido, obteve-se, para cada real investido, retorno de 1,32 e 1,24 real, respectivamente, para a suplementação com grão de milheto triturado fornecido três vezes por semana e diariamente. Embora a suplementação diária com grão de milheto triturado tenha propiciado maior ganho de peso, resultou também em maiores gastos. Assim, a forma de suplementação de melhor resultado econômico foi com milheto triturado ofertado três vezes por semana, devido aos menores gastos com distribuição dos suplementos.

Com relação à frequência de suplementação, a remuneração do capital investido foi de 78,96 e 132,29\% para milheto inteiro e triturado, respectivamente, valores que comprovam que a redução na frequência de suplementação exclusivamente não aumenta o retorno econômico; é uma ferramenta de manejo que deve ser associada a tecnologias (por exemplo à moagem dos grãos) que melhorem ou mantenham o ganho de peso dos animais em comparação à suplementação diária. A suplementação diária teve maior custo, sobretudo em decorrência dos gastos com mão-de-obra.

Tabela 5 - Indicadores zootécnicos e econômicos e respectivos valores para cada tratamento

\begin{tabular}{|c|c|c|c|c|c|}
\hline \multirow[t]{2}{*}{ Indicadores } & \multirow{2}{*}{$\begin{array}{l}\text { Mistura } \\
\text { mineral }\end{array}$} & \multicolumn{2}{|c|}{ Milheto inteiro } & \multicolumn{2}{|c|}{ Milheto triturado } \\
\hline & & $3 \mathrm{X} / \mathrm{semana}$ & $7 \mathrm{X} /$ semana & $3 \mathrm{X} /$ semana & $7 \mathrm{X} /$ semana \\
\hline Ganho em peso total (kg/animal) & $-13,44$ & 18,48 & 20,16 & 30,24 & 31,92 \\
\hline Ganho em peso diário (g/animal/dia) & $-160,00$ & 220,00 & 240,00 & 360,00 & 380,00 \\
\hline Ganho em peso diferencial (g/animal/dia) & - & 380,00 & 400,00 & 520,00 & 540,00 \\
\hline Receita (R\$/animal) & $-41,47$ & 57,02 & 62,20 & 93,30 & 98,48 \\
\hline Custo do transporte (R\$/animal) & 5,25 & 12,27 & 36,96 & 12,27 & 36,96 \\
\hline Custo da mão-de-obra (R\$/animal) & 8,82 & 21,00 & 63,00 & 21,00 & 63,00 \\
\hline Custo total $(\mathrm{R} \$ /$ animal $)$ & 9,52 & 72,21 & 77,20 & 70,53 & 78,88 \\
\hline Custoda@produzida (R\$) & - & 112,71 & 110,46 & 67,28 & 71,28 \\
\hline Valor pago pela@ no período (R\$/@) & 89,00 & 89,00 & 89,00 & 89,00 & 89,00 \\
\hline Margem bruta de lucro (R\$/animal) & $-50,99$ & $-15,19$ & $-15,00$ & 22,77 & 19,61 \\
\hline
\end{tabular}

Rendimento de carcaça - 52\%; Valor da @ do boi no período (10/2008) - R\$ 89,00; Salário mínimo (10/2008) - R\$ 415,00; Valor do dólar no período (10/2008) - R\$2,16. 
Embora nem todas as estratégias de suplementação tenham sido economicamente atraentes em uma primeira análise, deve-se atentar aos benefícios indiretos dessa técnica, principalmente pela redução na idade ao abate, que resulta na desocupação das pastagens para outros animais, acarretando, com isso, em maior giro do capital.

Paula et al. (2010) também encontraram melhor retorno econômico para a suplementação três vezes por semana e, segundo os autores, os menores custos envolvidos no processo de distribuição dos suplementos na frequência de três vezes por semana permitiram melhores retornos econômicos em comparação à suplementação diária.

Figueiredo et al. (2007) analisaram quatro estratégias de suplementação para abate aos 18, 24, 30 e 40 meses e encontraram, entre as estudadas, melhores resultados econômicos para o abate aos 18, 30 e 24 meses, respectivamente, sendo a estratégia de abate aos 40 meses economicamente insustentável a curto prazo. Também concluíram que a suplementação de bovinos em pastagens tropicais é uma alternativa economicamente viável para recria e terminação de machos de corte.

Do ponto de vista estratégico, pode-se inferir que o ambiente de comercialização da arroba produzida e o custo dos ingredientes utilizados na formulação dos suplementos assumem grande importância nas análises econômicas e, consequentemente, na tomada de decisões, uma vez que qualquer alteração favorável de mercado pode incrementar os índices econômicos (Paula et al., 2010).

\section{Conclusões}

A suplementação concentrada a bovinos de corte em pastejo no período da seca proporciona maior desempenho em relação à suplementação apenas com mistura mineral. $\mathrm{O}$ processamento do grão de milheto, independentemente da frequência de fornecimento dos suplementos, promove maior desempenho animal. O grão de milheto triturado, aliado à oferta em dias alternados, é a estratégia mais economicamente atrativa. Animais sob suplementação apenas com mistura mineral tem maior tempo em pastejo em comparação àqueles sob suplementação com concentrado independentemente da frequência de suplementação e forma física do grão.

\section{Referências}

BASTOS, A.O.; MOREIRA, I.; FURLAN, A.C. et al. Composição química, digestibilidade dos nutrientes e da energia de diferentes milhetos (Pennisetum glaucum (L.) R.Brown) em suínos. Revista Brasileira de Zootecnia, v.34, n.2, p.520-528, 2005.
BEAUCHEMIN, K.A.; McALLIESTER T.A.; DONGY Y. et al. Effects of mastication on digestion of whole cereal grains by cattle. Journal Animal Science, v.72, p.236, 1994.

BERCHIELI, T.T.; CANESIN, R.C.; ANDRADE, C. Estratégias de suplementação para ruminantes em pastagens. In: REUNIÃO ANUAL DA SOCIEDADE BRASILEIRA DE ZOOTECNIA, 43., 2006, João Pessoa. Anais... João Pessoa, 2006. (CD-ROM)

BOHNERT, D.W.; SCHAUER, C.S.; DELCURTO, T. Influence of rumen protein degradability and supplementation frequency on performance and nitrogen use in ruminants consuming lowquality forage: Cow performance and eficiency of nitrogen use in wethers. Journal of Animal Science, v.80, p.1629-1637, 2002 .

BOLZAN, I.T.; SANCHEZ, L.M.B.; CARVALHO, P.A. et al Consumo e digestibilidade em ovinos alimentados com dietas contendo grão de milho moído, inteiro ou tratado com uréia, com três níveis de concentrado. Ciencia Rural, v.37, n.1, p.229-234, 2007.

CANESIN, R.C.; BERCHIELLI, T.T.; ANDRADE, P. Desempenho de bovinos de corte mantidos em pastagem de capim-marandu submetidos a diferentes estratégias de suplementação no período das águas e da seca. Revista Brasileira de Zootecnia, v.36, n.2, p.411-420, 2007.

CASALI, A.O.; DETMANN, E.; VALADARES FILHO, S.C. et al. Influência do tempo de incubação e do tamanho de partículas sobre os teores de compostos indigestíveis em alimentos e fezes bovina obtidos por procedimentos in situ. Revista Brasileira de Zootecnia, v.37, n.2, p.335-342, 2008 .

CHACON, E.; STOBBS, T.H. Influence of progressive defoliation of a grass sward on the eating behaviour of cattle. Australian Journal Agriculture, v.27, p.709-727, 1976.

EUCLIDES, V.P.B.; CARDOSO, E.G.; MACEDO, M.C.M. et al. Consumo voluntário de Brachiaria decumbens cv. Basilisk e Brachiaria brizantha cv. Marandu sob Pastejo. Revista Brasileira de Zootecnia, v.29, n.6, p.2200-2208, 2000.

EUCLIDES, V.P.B.; EUCLIDES FILHO, K.; COSTA, F.P. et al. Desempenho de novilhos F1s Angus-Nelore em pastagens de Brachiaria decumbens submetidos a diferentes regimes alimentares. Revista Brasileira de Zootecnia, v.30, n.2, p.470-481, 2001.

EUCLIDES, V.P.B. Produção intensiva de carne bovina em pasto. In: SIMPÓSIO DE PRODUÇÃO DE GADO DE CORTE, 2. 2001, Viçosa, MG. Anais... Viçosa, MG, 2001. p.55-82.

FIGUEIREDO, D.M.; OLIVEIRA, A.S.; SALES, M.F.L. et al. Análise econômica de quatro estratégias de suplementação para recria e engorda de bovinos em sistema pasto-suplemento. Revista Brasileira de Zootecnia, v.36, n.5, p.1443-1453, 2007.

GARCIA, L.F.; FERNANDES, L.B.; FRANCO, A.V.M. et al. Desempenho de bovinos em pastejo contínuo submetidos a dois intervalos de suplementação no período da seca. In: REUNIÃO ANUAL DA SOCIEDADE BRASILEIRA DE ZOOTECNIA, 42. 2005, Goiânia. Anais... Goiânia, 2005. (CD-ROM).

GOMES JÚNIOR, P.; PAULINO, M.F.; DETMANN, E. et al. Desempenho de novilhos mestiços na fase de crescimento suplementados durante a época seca. Revista Brasileira de Zootecnia, v.31, n.1, p.139-147, 2002.

HALL, M.B. Neutral detergent-soluble carbohydrates: nutritional relevance and analysis, a laboratory manual. Gainesville: University of Florida, 2000. (Extension Bulletin, 339).

HODGSON, J. Grazing managemete: science into practice. New York: John Wiley e Sons, 1990. 203p.

JOHNSON, A.D. Sample preparation and chemical analysis of vegetation. In: t'MANNETJE, L. (Ed.). Measurement of grassland vegetation and animal production. Aberystwyth Commonwealth Agricultural Bureaux, 1978. p.96-102.

LAMPIERRE, H.; LOBLEY, G.E. Nitrogen recycling in the ruminant. Journal Dairy Science, v.84 (E Suppl.), p.223-236, 2001.

LAZZARINI, I.; DETMANN, E.; SAMPAIO, C.B. et al. Intake and digestibility in cattle fed low-quality tropical forage and 
supplemented with nitrogenous compounds. Revista Brasileira de Zootecnia, v.38, n.10, p.2021-2030, 2009.

MERTENS, D.R. Regulation of the forage intake. In: FAHEY JR., G.C.; COLlins, M.; MERTENS, D.R. et al. (Eds). Forage quality evaluation and utilization. Nebrasca: American Society of Agronomy, Crop Science of America; Soil Science of America, 1994. 988p.

MERTENS, D.R. Gravimetric determination of amylase treated neutral detergent fiber in feeds with refluxing in beakers or crucibles: collaborative study. Journal of AOAC International, v.5, n.6, p.1212-1240, 2002.

MINSON, D.J. Forage in ruminant nutrition. San Diego: Academic Press, 1990. 483p.

MORAES, E.H.B.K.; PAULINO, M.F.; VALADARES FILHO, S.C. et al. Avaliação nutricional de estratégias de suplementação para bovinos de corte durante a estação da seca. Revista Brasileira de Zootecnia, v.39, n.3, p.608-616, 2010.

MORON, I.R.; TEIXEIRA, J.C.; OLIEIRA, A.I.G. et al. Cinética da digestão ruminal do amido dos grãos de milho e sorgo submetidos a diferentes formas de processamento. Ciencia e Agrotecnologia, v.24, n.1, p.208-212, 2000.

NATIONAL RESEARCH COUNCIL - NRC. Nutrients requirements of dairy cattle. 7.ed. Washington, D.C.: National Academy Press, 2001. 381p.

PAULA, N.F.; ZERVOUDAKIS, J.T.; CABRAL, L.S. et al. Frequência de suplementação e fontes de proteína para recria de bovinos em pastejo no período seco: desempenho produtivo e econômico. Revista Brasileira de Zootecnia, v.39, n.4, p.873-882, 2010. PAULINO, M.F.; FIGUEIREDO, D.M.; MORAES, E.H.B.K. et al. Suplementação de bovinos em pastagens: uma visão sistêmica.
In: SIMPÓSIO DE PRODUÇÃO DE GADO DE CORTE, 4. 2004, Viçosa, MG. Anais... Viçosa, MG: SIMCORTE, 2004. p.93-144.

SAMPAIO, C.B.; DETMANN, E.; LAZZARINI, I. et al. Rumen dynamics of neutral detergent fiber in cattle fed low-quality tropical forage and supplemented with nitrogenous compounds. Revista Brasileira de Zootecnia, v.38, n.3, p.560-569, 2009.

SANTOS, E.D.G.; PAULINO M.F.; QUEIROZ, D.S. et al. Avaliação de pastagem diferida de Brachiaria decumbens stapf.2 disponibilidade de forragem e desempenho animal durante a seca. Revista Brasileira de Zootecnia, v.33, n.1, p.214-224, 2004.

SILVA, D.J.; QUEIROZ, A.C. Análise de alimentos: métodos químicos e biológicos. 3.ed. Viçosa, MG: UFV, Imprensa Universitária, 2002. 165p.

SNIFFEN, C.J.; O'CONNOR, J.D.; VAN SOEST, P.J. et al. A net carbohydrate and protein system for evaluating cattle diets: II. Carbohydrate and protein availability. Journal of Animal Science, v.70, n.11, p.3562-3577, 1992.

VALADARES FILHO, S.C.; PINA, D.S. Fermentação Ruminal. In BERCHIELLI, T.T.; PIRES A.V.; OLIVEIRA, S.G. (Eds.) Nutrição de ruminantes. Jaboticabal: Funep, 2006. v.1, p. 151-182.

VALADARES FILHO, S.C.; PAULINO, P.V.R.; MAGALHÃES, K.A. Exigências nutricionais de zebuínos e tabela de composição de alimentos BR-CORTE. Viçosa, MG: UFV, 2006. 142p.

VAN SOEST, P.J.; ROBERTSON, J.B. Analysis of forages and fibrous foods. Ithaca: Cornell University, 1985. 202p.

VAN SOEST, P.J. Nutritional ecology of the ruminant. 2.ed. Ithaca: Cornell University, 1994. 476p. 